\title{
Developing the Algorithm of Delineation \\ of Low-Velocity Ground Layer \\ in a Higher-Velocity Layer as Part \\ of the Refraction Survey for Seismic Safety Inspection of Techno Sphere Objects
}

\author{
Vasiliy A. Mironov a** and Anastasia A. Karyukina ${ }^{\mathrm{b}}$ \\ ${ }^{a}$ Environmental Center Sustainable Management \\ of Natural Resources \\ 53 Mira, Krasnoyarsk, 660049, Russia \\ ${ }^{b}$ State Enterprise of the Krasnoyarsk Territory \\ "Krasnoyarsk Research Institute of Geology \\ and Mineral Resources" \\ 55 Mira, Krasnoyarsk, 660049, Russia
}

Received 22.11.2014, received in revised form 15.12.2014, accepted 09.02.2015

The refraction survey is based on registration of refraction elastic waves away from the source. Refraction waves travel time during processing gives information about the layers cover thickness and their form. You can get the mentioned data on condition that the elastic waves velocity from layer to layer in the ground gets higher in the depth. However, there are cases when there occur low-velocity layers among high-velocity ones in the ground in question. Therefore there is necessity for solving this problem within the investigated method. In the worked-out algorithm no new software packages have been invented, but the opportunities of already known software packages have been used (RadExPro, in our case), along with using miscellaneous calculations and graphic editors.

Keywords: method of refraction, the layers of geological formations, the seismic safety.

(c) Siberian Federal University. All rights reserved

* Corresponding author E-mail address: vasya-kun@mail.ru 


\title{
Разработка алгоритма выявления
}

низкоскоростной прослойки грунта

в более высокоскоростном слое

\author{
в рамках метода преломленных волн
}

Для оценки сейсмической безопасности

техносферных объектов

\author{
В.А. Миронов ${ }^{a}$, А.А. Карюкина ${ }^{6}$ \\ аЭкологический центр рационального освоения природных ресурсов \\ Россия, 660049, Красноярск, пр. Мира, 53 \\ ${ }^{\sigma}$ Красноярский научно-исследовательский институт геологии \\ и минерального сырья \\ Россия, 660049, Красноярск, пр.Мира, 55
}

\begin{abstract}
Изложен метод преломленных волн, основанный на регистрациии преломленных упругих волн вдали от источника. Распространение преломленных волн в проиессе обработки дает данные о глубинах залегания слоев геологических образований, их форме и толщине покрытия. Перечисленные данные можно получить при условии того, что скорость упругих волн в грунте от слоя к слою возрастает с глубиной. Однако бывают случаи, когда встречаются низкоскоростные прослойки, данные о которых также необходимо предоставить в результате обработки. Таким образом, существует необходимость в решении этой проблемы в рамках исследуемого метода. В разработанном алгоритме не применяются новые программные пакеты, но возможности уже известных пакетов программного обеспечения были использованы (RadExPro, в намем случае) наряду с различными расчетами и графическими редакторами.
\end{abstract}

Ключевые слова: метод преломленных волн, слои геологических образований, сейсмическая безопасность.

Метод преломленных волн (МПВ) основан на регистрации преломленных упругих волн вдали от источника, скользящих вдоль верхней части слоя (кровли) геологических образований [1]. При этом большую часть своего пути упругие волны проходят приблизительно горизонтально по кровле слоев, в которых скорость их распространения больше по сравнению со скоростью в соседних вышележащих слоях. По времени пробега данных преломленных волн в процессе обработки получают данные о глубинах залегания этих слоев, их форме и, в отдельных случаях, об их литологии.

Особенностью МПВ является возможность наблюдать при залегании слоистой толщи на однородном слое большой мощности преломленную от нижней части слоя (подошвы) волну на таком расстоянии от источника, при котором она приходит к поверхности раньше всех других волн (метод первых вступлений) [2]. При проведении работ по методу преломленных волн используют системы наблюдений, обеспечивающие надежное распознавание волн и их прослеживание по всей изучаемой площади, что достигается при наблюдениях по системе встречных или нагоняющих годографов, которые характеризуют зависимость времени

$$
-109-
$$


пробега волны, распространяющейся от источника до приемника волны (регистрирующего устройства) [3].

Известное свойство горных пород сопротивляться изменениям размеров или формы и возвращаться в первоначальное недеформированное состояние называют упругостью. Мерой изменения формы и размеров породы является характеристика относительной деформации. Количественно меру воздействия на горные породы источников сейсмических волн измеряют напряжением - силой, действующей на единицу площади. Связь между величиной приложенного напряжения и параметрами возникшей деформации устанавливается законом Гука. Если эта связь линейна, то такие тела принято называть абсолютно упругими. При малых и кратковременных деформациях, обычно возникающих при сейсмических исследованиях, большинство горных пород можно считать идеально (абсолютно) упругими. Если связь между напряжением и деформацией в теле имеет более сложный вид зависимости, то такие породы называют пластическими или не абсолютно упругими [4].

Возникшие в районе действия источника напряжения, они распространяются (передаются) в среде от точки к точке во все стороны от источника. Данный процесс является процессом распространения упругих волн в среде. При воздействии источника упругих волн на горные породы происходит процесс передачи энергии и ее распространения в виде сейсмической волны.

Согласно теории распространения упругих волн в безграничном изотропном пространстве могут возникать и распространяться два независимых типа сейсмических волн. Первый тип волн - продольные сейсмические волны $P$ (prima - первый), они наиболее быстрые и приходят от источника к любой точке наблюдения первыми. Обозначают скорость распространения $P$-волны $V_{p}$. Второй тип сейсмических волн называют поперечными, или $S$-волнами (secundaвторой). Скорость распространения $S$-волны обозначают $V_{s}$.

Эти типы волн различаются характером смещения точек среды в момент прохождения сейсмических волн (рис. 1). На данном рисунке показаны частицы горных пород среды («шарики»). Стрелками обозначены длина волны $\lambda$ и направления: смещения частицы среды при прохождении $P$-волны (1), смещения частицы среды при прохождении $S$-волны (2), движения волны (3). На рис. 1а показано, что направление движения частиц среды для $P$-волн совпадает с направлением распространения волны. На рисунке 1 видно, что направление движения частиц для $S$-волн перпендикулярно направлению распространения волны.

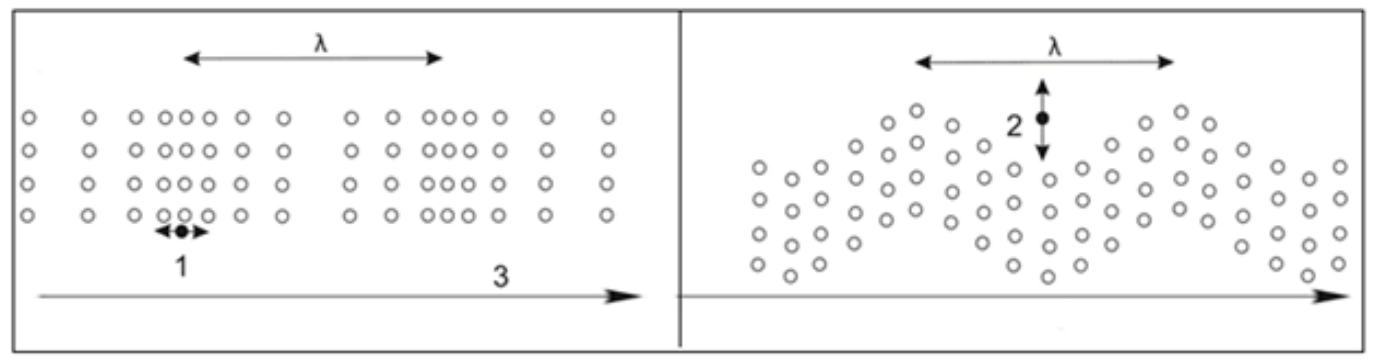

$a$

$\sigma$

Рис. 1. Пример геологической среды при прохождении $P$-волн (a) и $S$-волн (б) 
В изотропном твердом теле для описания процесса распространения упругих волн используют упругие модули Ламе $\mu$ и $\varepsilon$. Связи параметров $\mu$ и $\varepsilon$ задаются выражением

$$
V_{P}=\sqrt{\frac{\varepsilon+2 \mu}{\rho}} ; V_{S}=\sqrt{\frac{\mu}{\rho}}
$$

где $\rho$ - плотность среды. Отношение скоростей $\frac{V_{P}}{V_{S}}$ может принимать значение, большее величины $\sqrt{2}$.

В 2014 г. были проведены геофизические полевые работы методом преломленных волн на особо ответственном объекте. Полевые исследования МПВ выполнены в соответствии с методикой одним отрядом с использованием двух цифровых 24-канальных инженерных сейсмостанций «Лакколит 24-М3», в результате выполнялась 48-канальная запись. В качестве источников упругих колебаний использовали удары ручного тампера (кувалды) массой 16 кг о специальную металлическую подставку, вкопанную в грунт. Применение такого способа возбуждения упругих колебаний позволяет получить достаточно разрешенную запись.

Сейсморазведочные работы проводили по отдельным линиям - сейсморазведочным профилям. Перед началом наземных работ намечали систему профилей. По каждому профилю располагались пункты возбуждения упругих волн и сейсмоприемники. При вертикальном расположении сейсмоприемник реагирует в основном на продольные волны, при горизонтальном - улавливает главным образом поперечные волны [1]. Вдоль профиля разматывается сейсмическая коса, которая подключается к сейсмоприемникам и блоку усилителей. Для точного отсчета времени прихода упругих волн нужно знать момент возбуждения. При использовании кувалды в момент удара на один из каналов подается электрический импульс.

Для возбуждение продольной волны наблюдения вели по схеме $Z-Z$ (вертикально направленное возбуждение и вертикальные сейсмоприемники). Возбуждение продольных волн осуществляется вертикально направленными ударами. Для получения поперечных волн $S H$ использовали схему $Y-Y$ (горизонтальные возбуждения в направлении, перпендикулярном линии профиля, и горизонтальные сейсмоприемники, ориентированные в том же направлении), волны возбуждаются горизонтально направленными ударами по стенкам шурфов глубиной 0,3 м. С целью однозначного опознания волн типа $S H$ получали записи с противоположно направленных ударов с применением разнополярного суммирования накоплений, за счет чего поперечная волна меняла фазу на противоположную, а продольная волна не меняла и гасилась.

Выносные пункты возбуждения располагались по линии профиля с удалением от концов интервала наблюдения на расстояние 46 м. В некоторых ситуациях данные интервалы изменялись в зависимости от местных условий на площадке. Регистрация данных проводилась по 4-точечной схеме наблюдения (рис. 2).

На рис. 2 показаны основные пункты возбуждения $O_{1}$ и $O_{2}$, фиксирующиме начало и конец профиля, и выносные - $O_{3}$ и $O_{4}$, которые располагались по линии профиля с удалением от концов интервала наблюдения на расстояние 46 м. Выносные пункты возбуждения необходимы для получения дополнительного материала о «мертвой» зоне, где отсутствует головная волна. Встречные годографы обозначены $t_{1}$ и $t_{2}$, а нагоняющие - $t_{3}$ и $t_{4}$. Встречные годографы - это годографы, полученные при постоянном расположении сейсмоприемников вдоль оси $X$ и двух 


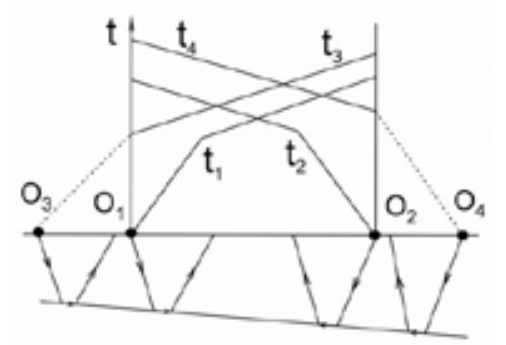

Рис. 2. 4-точечная схема наблюдений в МПВ: лучи и годографы

пунктов возбуждения, расположенных в начале и конце расстановки. Нагоняющие годографы годографы преломленных волн, полученные на одном интервале $x$ с двух пунктов взрыва.

На данном объекте мы не единожды столкнулись с вышеуказанной проблемой, когда при обработке данных по поперечным $S$-волнам встречаются «разрывные по времени» первые вступления (разрывы по времени не наблюдались для более высокоскоростных продольных $P$-волн на исследуемом участке грунта). Данная проблема возникает из-за того, что в высокоскоростных слоях грунта встречаются низкоскоростные прослойки, например, суглинки сменяются нижележащим слоем песка. При этом известно, что скорость упругих поперечных $S$-волн в суглинках выше, чем у песков.

В используемых программных пакетах для обработки сейсмических данных учитывают условие, что скорость с увеличением глубины возрастает от слоя к слою. В данном случае при полученном материале невозможно использовать стандартную методику в программных пакетах для расчета глубины залегания низкоскоростных прослоек. Поэтому возникла необходимость разработки алгоритма выявления низкоскоростных прослоек грунта в более высокоскоростных слоях.

В предложенном алгоритме никаких новых программных пакетов не разрабатывалось, а использовались возможности уже применяемых пакетов (в нашем случае программный пакет RadExPro) с дополнительными вычислениями и графическими редакторами.

Программный пакет RadExPro позволяет обрабатывать многоканальные сейсмоакустические данные. Включенные процедуры позволяют осуществлять основные операции:

- ввод данных. При этом реализованы дополнительные возможности, позволяющие автоматически определять количество трасс в файле и шаг по профилю;

- интерполяцию данных на регулярную сеть наблюдений, что используется, например, для объединения различных файлов данных в один профиль;

- обработку и анализ данных;

- вывод данных в виде визуализации результатов и твердой копии.

Программный пакет RadExPro может осуществлять внутри одной системы весь процесс обработки данных сейсморазведки: чтение и визуализацию сейсмограмм, редактирование трасс (запись одного сейсмоприемника), корреляцию вступлений волн, построение и редактирование годографов, определение сейсмических скоростей и построение преломляющих границ. При возникновении каких-либо сбоев в результатах реализована возможность возврата на несколько шагов назад для корректировки данных или повторной обработки части материала. 
RadExPro является специализированным пакетом, он позволяет проводить обработку и интерпретацию данных: наземной и морской высокоразрешающей сейсморазведки МПВ, а также анализ поверхностных волн [5].

На рис. 3 представлен полевой материал (сейсмограмма), показывающий наличие низкоскоростной прослойки. Первые вступления прерываются и возобновляются уже ниже по оси времени («разрывные» первые вступления).

По разработанному алгоритму выделяем два варианта первых вступлений (рис. 3). По первому в программе строят годографы, рассчитываются глубины и скорости сейсмических волн в слоях грунта без учета низкоскоростной прослойки. Таким образом, выявляется верхняя граница второго (лежащего ниже прослойки) высокоскоростного слоя. По второму годографу рассчитываем глубину (верхнюю границу) первого (лежащего выше прослойки) высокоскоростного слоя. При этом все слои до высокоскоростного объединяем в один. Таким образом, получаем только одну границу.

На рис. 4 видны изображения слоев, глубин и скоростей по двум построенным годографам. Таким образом, между верхними границами первого и второго высокоскоростных слоев находится низкоскоростная прослойка.

Далее производятся дополнительные вычисления по следующей формуле:

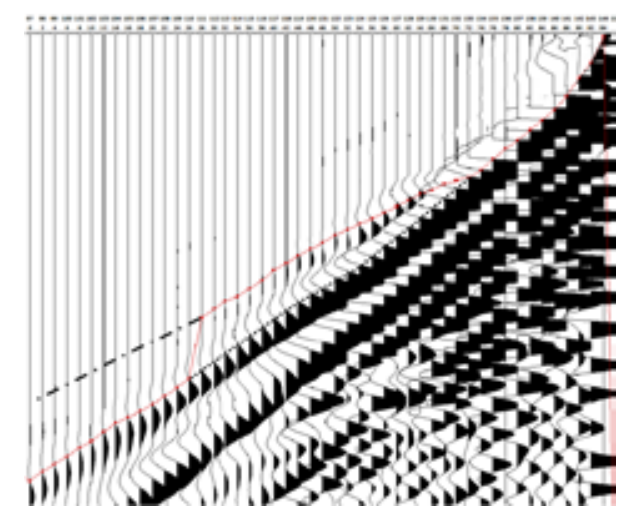

(a)

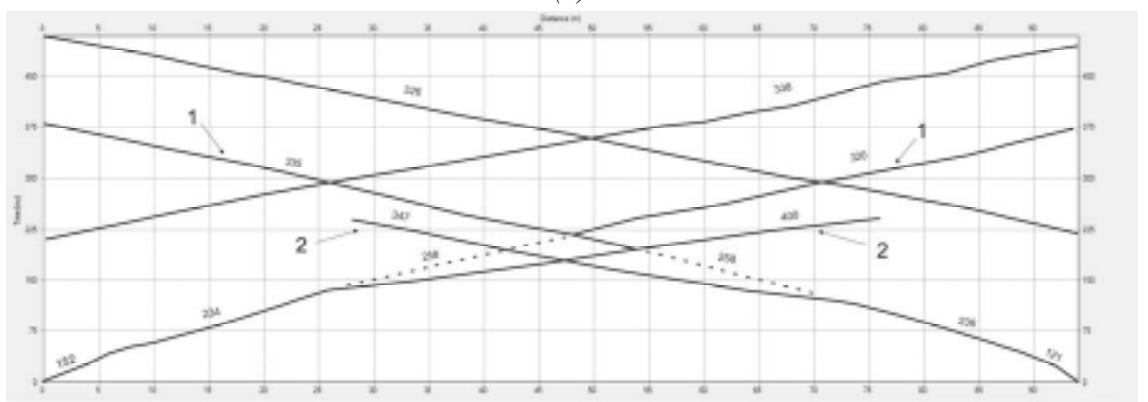

(б)

Рис. 3. Построение годографов по первым вступлениям: (a) - первые «разрывные по времени» вступления; (б) - годографы, построенные по первым вступлениям: 1 - без учета низкоскоростной прослойки в грунте по нижним вступлениям (обозначен пунктирной линией на части $(a)$ ); 2 - по верхним вступлениям и продолженный так, как будто разрыва во времени не происходило (обозначен штрихпунктирной линией) 


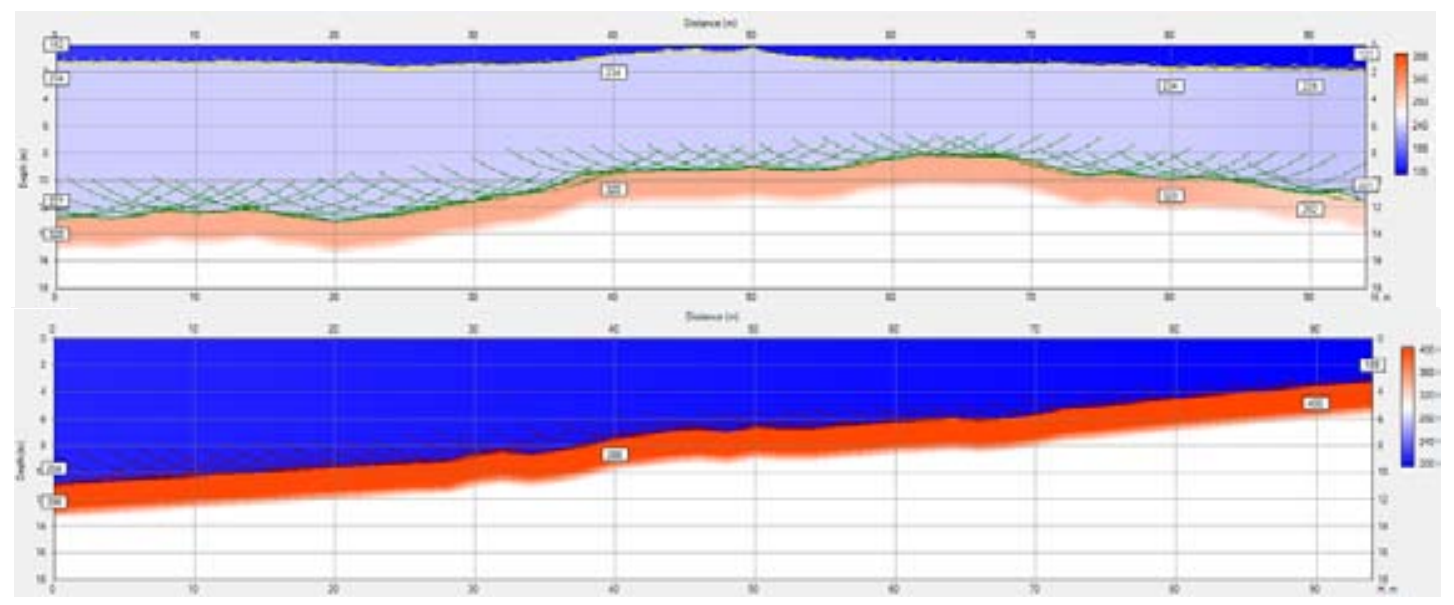

Рис. 4. Изображение границы слоев, глубины и скоростей волн по годографу, построенному без учета низкоскоростной прослойки (верхняя часть рисунка), и по годографу, построенному без разрыва по времени (нижняя часть рисунка)

$$
H=\frac{\Delta x}{2} * \sqrt{\frac{v_{2}-v_{1}}{v_{2}+v_{1}}},
$$

где $H$ - мощность низкоскоростной прослойки, м; $v_{1}$ - скорость волны в низкоскоростной прослойке, м/с; $v_{2}$ - скорость волны в высокоскоростном слое, м/с; $\Delta x$ - приращение расстояния вдоль профиля, где регистрируется скорость низкоскоростной прослойки, м.

На верхней части рис. 3 по прямому годографу видно, что $v_{1}=258 \mathrm{~m} / \mathrm{c}, v_{2}=320 \mathrm{~m} / \mathrm{c}, \Delta x=$ 20 м. По встречному годографу $v_{1}=258 \mathrm{~m} / \mathrm{c}, v_{2}=335 \mathrm{~m} / \mathrm{c}, \Delta x=16$ м. Получаем, что с правой и с левой сторон рассматриваемого скоростного разреза мощность низкоскоростной прослойки составляет 3,27 и 2,88 м соответственно.

Так как низкоскоростная прослойка лежит между первым и вторым высокоскоростными слоями, а по построенным годографам видно, что верхняя граница второго слоя второго высокоскоростного слоя является нижней границей низкоскоростной прослойки, то найденную мощность $H$ откладываем вверх от глубины залегания второго высокоскоростного слоя. Итоговое построение скоростного грунтового разреза представлено в нижней части рис. 5. Полученные данные в результате обработки упомянутый методикой подтверждаются другим сейсмическим методом - вертикальным сейсмическим профилированием - и геологией, которую получали в результате бурения скважины на исследуемом участке. На рис. 6 изображена блок-схема предложенного алгоритма выявления низкоскоростной прослойки грунта в более высокоскоростном слое.

В ходе выполненной работы получены следующие результаты:

- проведены полевые работы методом преломленных волн на исследуемом участке;

- получен скоростной грунтовый разрез поперечных волн на участке работ;

- разработан алгоритм выявления низкоскоростной прослойки грунта в более высокоскоростном слое. 


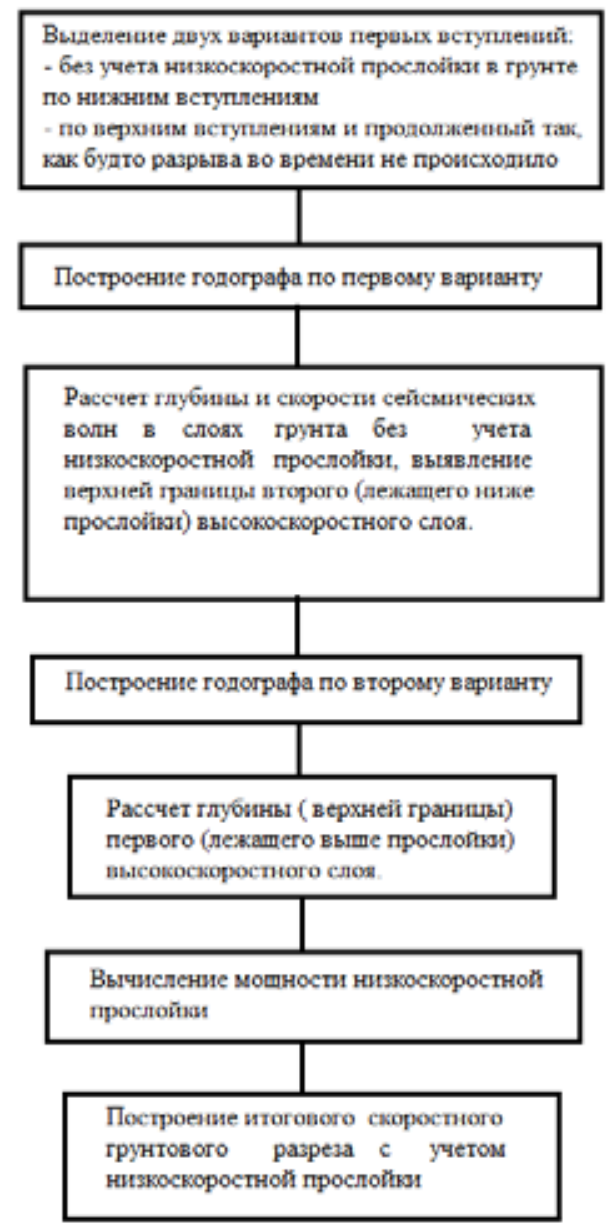

Рис. 5. Построение годографов и итоговое построение скоростного грунтового разреза

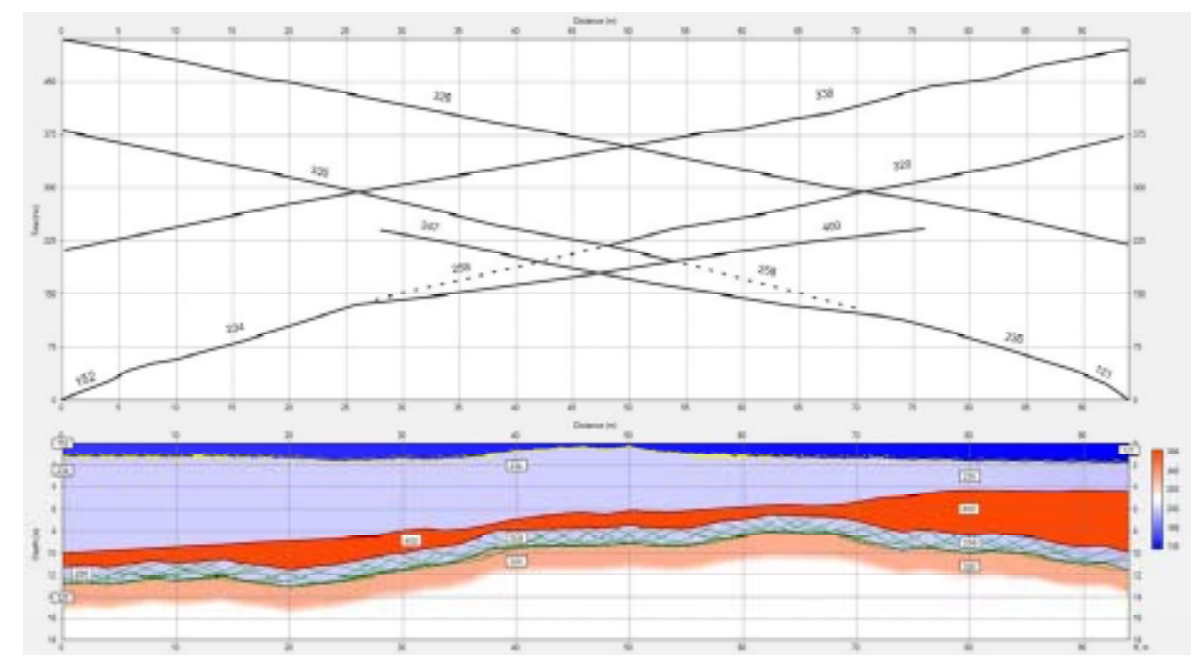

Рис. 6. Блок-схема предложенного алгоритма выявления низкоскоростной прослойки грунта в более высокоскоростном слое 
Полученные данные о слоях грунта (мощность и скорость распространения упругих волн) необходимы для реализации других методов (например, метод сейсмических жесткостей) для оценки относительных изменений (приращений) сейсмической балльности на исследуемом участке.

\section{Список литературы}

[1] Аплонов С.В. Геодинамика: учебник. СПб.: Изд-во С.-Петерб. ун-та, 2001. 360 с.

[2] Гайнанов В.Г. Сейсморазведка. М.: МГУ, 2005. 148 с.

[3] Пантелеев В.Л. Физика Земли и планет / МГУ им. М. В. Ломоносова. Физический факультет. Курс лекций. М., 2001. 117 с.

[4] Бондарев В.И. Основы сейсморазведки: учебное пособие для вузов. Екатеринбург: Издво УГГТА 5, 2003, 2003. $332 \mathrm{c.}$

[5] RadExPro 2013.1 Руководство пользователя [Электронный ресурс]: ООО «Декогеофизика СК» / Научный парк МГУ, 2013. - Режим доступа: http://www.radexpro.ru 